\title{
Comparison of the Physicochemical Characteristics of Pinus koraiensis L. Nut Oils from Different Extraction Technologies
}

\author{
HOU Lixia*, LI Cuicui, QIU Jihong
}

College of Food Science and Technology, Henan University of Technology, Zhengzhou 450001, China

\begin{abstract}
In this study, the physicochemical properties, fatty acid profiles, and tocopherol compositions of Pinus koraiensis L. nut oils were evaluated, and the impact of different extraction technologies on the overall quality of pine nut oil was assessed. All the pine nut oils had pleasant and characteristic odor and flavor of the pine nuts and the flavor of the oil from hot-pressing was strongest. The oils obtained by hexane extraction and sub-critical extraction had less deterioration, indicating hexane extraction and sub-critical extraction preserve the oil quality well. Gas chromatography showed that the predominant fatty acid was linoleic acid $(45.36 \%-45.91 \%)$, followed by oleic acid $(26.91 \%-27.10 \%)$, and pinolenic acid $(13.33 \%-13.63 \%)$, respectively. The oils from hexane extraction of cold-pressed cake and sub-critical extraction were richer in tocopherols and tocotrienols, namely, 37.52 and $36.18 \mathrm{mg} / 100 \mathrm{~g}$, respectively, with $\alpha$-tocopherol most abundant. The pine nut oils from hexane extraction of cold-pressed cake, hexane extraction, cold pressing, and sub-critical extraction had better oxidation stability with the oxidation induction times of 6.91, 5.27, 4.96 and $4.93 \mathrm{~h}$, respectively. Based on its features, P. koraiensis nut oil may have the multiple application in edible oil, cosmetic, and pharmaceutical industry. P. koraiensis can be one of the good woody candidates for closing the gap between the demand and production of vegetable oils.
\end{abstract}

Keywords: Pinus koraiensis nut oil; Physicochemical properties; Fatty acid composition; Tocopherols

\section{Introduction}

Woody oil plants don't occupy the cultivated land needed for crops production, and thus the development of the woody oil industry has become one of the important ways to close the gap between supply and demand for oil.

About 20000 tons of pine nuts are produced yearly in the world. China, Russia (Siberia), Korea and Pakistan are the main exporting countries ${ }^{[1]}$, and Pinus koraiensis L. is the chief pine species in China. Pine nuts are rich in protein and fat, with unsaturated fatty acid in the pine nut up to $85 \%$. Laboratory studies showed that $P$. koraiensis nut oil increases the antioxidant activity of rat serum and decreases lipid peroxidation ${ }^{[2]}$, which may be ascribed to fatty acid composition and other minor components in pine nut oil. Currently, the industrial oil extraction technologies include cold or hot pressing, solvent extraction and hexane extraction of cold-pressed cake, and the specifics depend on the kind of oilseeds and the ultimate use of the oil. Subcritical extraction technology, also called low temperature pressure extraction technology, is carried out at lower pressure and temperature, and obtains a higher extraction yield compared with supercritical fluid extraction ${ }^{[3]}$. Subcritical extraction technology also has the advantages of short extraction time, low environmental impact and low residual solvent ${ }^{[4]}$.

Some efforts have been made to understand the physicochemical

Received: 17 April 2018 /Accepted: 5 July 2018.

Supported by Henan Provincial Scientific and Technological Research Project (No.15210221027).

*Corresponding author. E-mail: hou1269@126.com

(CHenan University of Technology 2018

HOU L X, LI C C, QIU J H. Comparison of the Physicochemical Characteristics of Pinus koraiensis L. Nut Oils from Different Extraction Technologies[J]. Grain \& Oil Science and Technology, 2018, 1(3): 113-118. properties of pine nut oil ${ }^{[5-7]}$, and the pine nut oils from different kinds ${ }^{[8-9]}$, different mountains ${ }^{[10]}$ have been compared. Bao et al. ${ }^{[1]}$ optimized ultrasonic-assisted aqueous enzymatic extraction of pine nut oil, and the effect of the two methods of extraction including the aqueous enzymatic and the solvent methods were compared ${ }^{[12]}$. In this study, $P$. koraiensis nut oils were obtained by different extraction technologies including hot-pressing, cold-pressing, hexane extraction, hexane extraction of cold-pressed cake, and sub-critical extraction. The physicochemical properties, fatty acid profiles, and tocopherol compositions of the different oils extracted were evaluated, and the impact of different extraction technologies on the overall quality of pine nut oils was assessed. The information obtained has valuable implications for assessing the $P$. koraiensis the potential as one of the woody candidates for closing the gap between the demand and production of vegetable oils.

\section{Materials and Methods}

\subsection{Materials}

Fresh $P$. koraiensis seeds were bought from the "Ruyi Local Speciality Store" in Heilongjiang Province, China. The seeds were dehulled manually. The dehulled pine seeds were packed in plastic bags and stored at $4{ }^{\circ} \mathrm{C}$. Oil was extracted from seeds within 5 days of being put into storage.

\subsection{Oil Extraction}

Oil samples, in duplicate, were prepared using five different methods of extraction, as described below.

Hot pressing: About $500 \mathrm{~g}$ of dehulled pine nuts were roasted at $180{ }^{\circ} \mathrm{C}$ for $25 \mathrm{~min}$, cooled to $(130 \pm 5){ }^{\circ} \mathrm{C}$, and then pressed under hydraulic pressure of $50 \mathrm{MPa}$ for $25 \mathrm{~min}$ using hydraulic press 180 (Henan Weihang Machinery Co. Ltd., 
Zhengzhou, China). The obtained oil was filtered through a double layer of Whatman filter paper $(0.45 \mu \mathrm{m})$, and stored at $-20{ }^{\circ} \mathrm{C}$ until analysis.

Cold pressing: About $500 \mathrm{~g}$ of dehulled pine nuts were directly pressed using the hydraulic press 180 under hydraulic pressure of $50 \mathrm{MPa}$ for $25 \mathrm{~min}$ at room temperature of $(25 \pm 5){ }^{\circ} \mathrm{C}$. For each sample, the extraction procedure was repeated three times, and the resultant oil was collected together and filtered.

Hexane extraction: About $500 \mathrm{~g}$ of dehulled nuts were ground to a powder and sieved to a mesh size of 35 then added to a beaker with hexane $(1: 1, V / V)$, and stirred thoroughly; the hexane extraction procedure was repeated three times. The solvent was removed by using the rotary evaporation apparatus RE52-86A (Shanghai Yarong Biochemical Instrument Co. Ltd., China).

Hexane extraction of cold-pressed cake: The pine nut cake produced by cold-pressing was pulverized, and subjected to hexane extraction as described in "Hexane extraction".

Sub-critical extraction: The oil from approximately $200 \mathrm{~g}$ of pulverized pine nuts was extracted using sub-critical extraction apparatus CBE-5L (Henan Sub-critical Biotechnology Co. Ltd., Anyang, China). The extraction conditions were as follows: extraction solvent, $n$-butane; flow rate, $77 \mathrm{~L} / \mathrm{h}$; extraction pressure, $0.5 \mathrm{MPa}$; temperature, $(21 \pm 5){ }^{\circ} \mathrm{C}$. The extraction was repeated three times.

\subsection{Analytical Methods}

The determination of protein, moisture, ash, and fat contents was performed using the methods of Association of Official Analytical Chemists ${ }^{[13]}$.

The fiber content was measured according to Van Soest et al. ${ }^{[14]}$.

The total sugar content was determined color-metrically based on absorption at $490 \mathrm{~nm}$ using glucose as the standard ${ }^{[15]}$.

The relative densities of the oils were measured using pycnometer method according to the National Standards of the People's Republic of China ${ }^{[16]}$. The determination of refractive index was performed at room temperature using an Abbe refractometer (Beijing Winxinyio Science and Technology Development of Co. Ltd., China).

The color was determined using a Lovibond Tintometer WSL (Zhengzhou Zhonggu Mechanical Equipment Co. Ltd., China). The viscosity of the oil samples was determined using a digital viscometer DJ-5S (Shanghai Hengping Scientific Instrument Co. Ltd., China). The rotor (no. 1) and the temperature probe were immersed in the oil sample. The speed of rotation was then adjusted so that the measured value was within $20 \%-90 \%$ of the measuring range, and the rotation speed and the reading were recorded.

The odor and flavor were determined by five trained panelists as follows: after being heated to $50{ }^{\circ} \mathrm{C}$, an oil sample of $10 \mathrm{~g}$ was whisked by glass bar, smelled, and tasted.

Iodine value, saponification value, acid value, and peroxide value were determined as described by the Association of Official Analytical Chemists ${ }^{[13]}$.

Oxidative stability of the pine nut oils was measured with the 743 Rancimat (Metrohm Co., Basel, Switzerland). The conditions were set at a temperature of $110{ }^{\circ} \mathrm{C}$, and an air flow rate of $20 \mathrm{~L} / \mathrm{h}$ with sample of $3 \mathrm{~g}$. Oxidative stability was expressed as the oxidative induction time ${ }^{[17]}$.

Fatty acid composition: Fatty acid methyl esters were prepared and analyzed as described by Rezig et al. ${ }^{[18]}$ using Gas chromatography (GC) with slight modifications. Briefly, the pine nut oil samples were methylated using $0.5 \mathrm{~mol} / \mathrm{L}$ $\mathrm{NaOH}$ in methanol solution and boron trifluoride-methanol, successively. The fatty acid methyl esters (FAME) in chloroform was analyzed by GC 7890B (Agilent Technologies, Wokingham, UK) equipped with FID detector under the following conditions: the temperatures of inlet, column, and detector were $210{ }^{\circ} \mathrm{C}$, $230{ }^{\circ} \mathrm{C}$, and $300{ }^{\circ} \mathrm{C}$, respectively. The flow rates of the nitrogen gas, the air, and the hydrogen gas were set as $1.0 \mathrm{~mL} / \mathrm{min}$, $400.0 \mathrm{~mL} / \mathrm{min}$, and $35.0 \mathrm{~mL} / \mathrm{min}$, respectively. The fatty acids were identified and quantified by comparing their retention times and areas with those of the FAME standards of known composition under the same conditions.

Tocopherol composition: Tocopherol composition was analyzed according to Przygoda et al. ${ }^{[19]}$ using HPLC (Waters e2695, USA) equipped with a fluorescence detector. The analysis conditions were as follows: column temperature, $25{ }^{\circ} \mathrm{C}$; hexane/isopropanol $(99: 1, V / V)$ as the mobile phase; excitation wavelength, $295 \mathrm{~nm}$; and emission wavelength, $330 \mathrm{~nm}$. The vitamin $\mathrm{E}$ were quantified based on an external calibration method using $\alpha$-, $\beta$-, $\gamma_{-}, \delta$-tocopherols, and $\alpha-, \beta-, \gamma-, \delta$-tocotripherols (Sigma Chemicals, US) as the standards.

\subsection{Statistical Analyses}

Microsoft Excel 2010 was used to carry out statistical analyses. The data were expressed as the mean \pm standard deviation (SD) of three independent experiments.

\section{Results and Discussion}

\subsection{Chemical Composition}

Table 1 shows that the pine nuts analyzed here had $17.41 \%$ protein, a value lower than that reported for $P$. halepensis Mill. (26.62\%), but comparable to $P$. pinaster $(16.25 \%)$ and P. canariensis $(16.71 \%)$, and higher than P. pinea L. $(14.25 \%)^{[20]}$. The variation in the protein content is most likely due to differences between the plant species and/or climate, geography and cultivation practices. The contents of crude fiber, total ash and total sugars in the P. koraiensis nuts were $10.78 \%, 2.81 \%$ and $0.02 \%$, respectively.

The $P$. koraiensis nuts has $68.67 \%$ crude fat, which is in accordance with that reported by Wolffet al. ${ }^{[21]}, 0.53-0.58$ times higher than that of $P$. pinea ${ }^{[22]}, 0.40-1.22$ folds higher than those reported for $P$. pinaster, $P$. nigra, $P$. griffithii, $P$. sylvestris, and

Table 1 Chemical composition of $P$. koraiensis nuts

\begin{tabular}{cc}
\hline Component & $\%$ (on dry weight basis) \\
\hline Crude fat & $68.67 \pm 0.93$ \\
Protein & $17.41 \pm 0.16$ \\
Crude fibre & $10.78 \pm 0.09$ \\
Total ash & $2.81 \pm 0.02$ \\
Total sugars & $0.02 \pm 0.001$ \\
Moisture content & $7.30 \pm 0.02$ \\
\hline
\end{tabular}


P. mughus $^{[21]}$, and $0.91-2.47$ times more than that of P. halepensis ${ }^{[23]}$.

The crude fat content of the pine nuts is also higher than that reported for the Cucurbita maxima L. seed ${ }^{[18]}$, Ximenia caffra L. and Ricinodendron rautanenii $\mathrm{L}$. nuts from Zimbabwe ${ }^{[24]}$, Arachis hypogaea L. ${ }^{[25]}$, and Torreya grandis L. kernel ${ }^{[26]}$, and approximately comparable to Corlylus avellana L. ${ }^{[27]}$ Combining its high yield and oil content, the $P$. koraiensis nuts have a great advantage as the promising resource for being used in the oil industry.

\subsection{Oil Yield}

Oil yield of pine nuts is illustrated in Table 2. The extraction rates for different technologies range from $45.91 \%$ to $55.38 \%$, in accordance with that summarised by Xie et al. ${ }^{[28]}$. The hexane extraction yielded the most oil of all the methods compared, and sub-critical extraction obtained the medium yield. The oil yield for different extraction processes in decreasing order is: hexane extraction $>$ hexane extraction of cold-pressed cake $>$ sub-critical extraction $>$ hot pressing $>$ cold pressing.

\subsection{Physicochemical Properties of Pine Nut Oils}

The color of the oil obtained by hexane extraction (HEO) and the oil obtained by sub-critical extraction (SEO) was pale yellow (Y30 R1.0 and Y30 R0.6, respectively) and transparent, while the oil obtained by hexane extraction of cold-pressed cake (HECCO) and the oil obtained by hot pressing (HPO) was yellow, and the latter was reddest of all the oils. The HPO had a strong, pleasant and characteristic odor and flavor of pine nuts, while that of the other oils was only slight, albeit characteristic. The oil obtained by cold pressing (CPO) had more water and unsaponifiable matter than oils from the other extraction processes, which render the oil opaque.

The relative density, viscosity, refractive index, saponification value and iodine value are important for assessing the quality of an oil. Relative densities and refractive indexes of the obtained oils were similar. HEO, HECCO and SEO had lower viscosity ranging from 80.77 to $85.03 \mathrm{MPa} \cdot \mathrm{s}$.

The saponification values reflect the $\mathrm{C}$-chain length of the fatty acids. For the oils tested here, saponification values ranged from $167.34 \mathrm{mg} \mathrm{KOH} / \mathrm{g}$ to $185.19 \mathrm{mg} \mathrm{KOH} / \mathrm{g}$, generally lower than those reported for Torreya grandis kernel oils ${ }^{[26]}$, indicating that the triacylglycerols of the pine nut oils had higher molecular weights, and HECCO (185.19 $\pm 6.45 \mathrm{mg} \mathrm{KOH} / \mathrm{g})$ had the smaller molecular weights than the oils form other extraction methods, while SEO ( $167.34 \mathrm{mg} \mathrm{KOH} / \mathrm{g}$ ) the highest molecular weights. Iodine value is an indicator of the degree of saturation of the fatty acids, and no significant difference was observed among the oil samples. The obtained oils had iodine values within the range of 137.14 and $141.61 \mathrm{~g} \mathrm{I}_{2} / 100 \mathrm{~g}$, higher than that of soybean oil ${ }^{[29]}$, T. grandis kernel oils ${ }^{[26]}$, and sunflower oil ${ }^{[30]}$. The results indicate that pine nut oils have more unsaturated fatty acids.

Acid value and peroxide value are the indicators of the oils deterioration. The acid values of the pine nut oils were within the range of $0.36-0.99 \mathrm{mg} \mathrm{KOH} / \mathrm{g}$, reaching the National Standard of the People's Republic of China for third-class soybean oil ${ }^{[31]}$. The acid values in decreasing order were HECCO $>$ HPO $>$ SEO $>\mathrm{HEO}>\mathrm{CPO}$. HECCO had a significant higher acid value than HEO $(P<0.05)$, indicating that pressing may increase the acid value, which is consistent with the finding of Kasote et al. ${ }^{[32]}$ The results may be attributed to the long extraction process including the cold-pressing extraction followed by the hexane extraction, in which cold pressing caused cells to break down, free fatty acids were released through enzymatic hydrolysis, and the acid value was increased.

While in terms of the peroxide values of $2.47-4.34 \mathrm{mmol} / \mathrm{kg}$, the pine nut oils meet the National Standard of the People's Republic of China for the first-class soybean oil ${ }^{[31]}$. The observed peroxide values were in decreasing order of $\mathrm{CPO}>$ $\mathrm{HECCO}>\mathrm{SEO}>\mathrm{HPO}>\mathrm{HEO}$. Combining the acid value and peroxide value, we can see that hexane extraction and sub-critical extraction yielded the oil with decent quality.

Based on the results, the $P$. koraiensis nut oils meet the National Standard of the People's Republic of China for the soybean oil ${ }^{[31]}$, indicating the oil is a good source of the edible oil. Furthermore, HEO and SEO was pale yellow and transparent, and had a pleasant and slight odor, meet the standard of Light industry Standard of the People's Republic of China for massage base oil and massage oil ${ }^{[33]}$, indicating that the pine nut oils obtained by hexane extraction, and sub-critical extraction may expand their application to the cosmetic industry.

\subsection{Fatty Acid Profile}

Table 3 shows the fatty acid compositions of pine nut oils. Overall, P. koraiensis nut oil has a high content of unsaturated

Table 2 Physicochemical parameters of pine nut oils

\begin{tabular}{|c|c|c|c|c|c|}
\hline Parameters & $\mathrm{CPO}$ & $\mathrm{HPO}$ & HEO & HECCO & SEO \\
\hline Oil yield (\%) & $45.91 \pm 2.01$ & $46.09 \pm 1.08$ & $55.38 \pm 2.15$ & $52.71 \pm 1.93$ & $49.71 \pm 1.26$ \\
\hline Color & Y5, R0.5 & Y30, R3.2 & Y30, R1.0 & Y40, R2.0 & Y30, R0.6 \\
\hline Relative density (d425) & $0.9269 \pm 0.0011$ & $0.9275 \pm 0.0013$ & $0.9225 \pm 0.0025$ & $0.9234 \pm 0.0022$ & $0.9205 \pm 0.0019$ \\
\hline Viscosity $(\mathrm{MPa} \cdot \mathrm{s})$ & $104.00 \pm 3.23$ & $115.84 \pm 3.78$ & $81.81 \pm 1.66$ & $80.77 \pm 4.72$ & $85.03 \pm 3.51$ \\
\hline Refractive index (n25) & $1.4718 \pm 0.0026$ & $1.4720 \pm 0.0041$ & $1.4729 \pm 0.0035$ & $1.4713 \pm 0.0086$ & $1.4704 \pm 0.0024$ \\
\hline Saponification value (mg KOH/g) & $184.31 \pm 6.79$ & $183.08 \pm 7.23$ & $178.33 \pm 5.64$ & $185.19 \pm 6.45$ & $167.34 \pm 5.01$ \\
\hline Iodine value $\left(\mathrm{g} \mathrm{I}_{2} / 100 \mathrm{~g}\right)$ & $137.14 \pm 3.29$ & $140.72 \pm 4.33$ & $138.89 \pm 3.55$ & $141.03 \pm 4.63$ & $141.61 \pm 4.89$ \\
\hline Acid value (mg KOH/g) & $0.36 \pm 0.01$ & $0.83 \pm 0.01$ & $0.51 \pm 0.02$ & $0.99 \pm 0.01$ & $0.64 \pm 0.02$ \\
\hline Peroxide value $(\mathrm{mmol} / \mathrm{kg})$ & $4.34 \pm 0.15$ & $2.72 \pm 0.11$ & $2.47 \pm 0.16$ & $3.66 \pm 0.13$ & $2.92 \pm 0.20$ \\
\hline Water and unsaponifiable matter (\%) & $0.07 \pm 0.01$ & $0.03 \pm 0.00$ & $0.05 \pm 0.01$ & $0.03 \pm 0.01$ & $0.03 \pm 0.01$ \\
\hline
\end{tabular}

Note: CPO: the pine nut oil obtained by cold pressing; HPO: the pine nut oil obtained by hot pressing; HEO: the pine nut oil obtained by hexane extraction; HECCO: the pine nut oil obtained by hexane extraction of cold-pressed cake; SEO: the pine nut oil obtained by sub-critical extraction. The same below. 
Table 3 Fatty acid compositions of the pine nut oils

\begin{tabular}{|c|c|c|c|c|c|}
\hline Fatty acid (\%) & $\mathrm{CPO}$ & HPO & HEO & HECCO & SEO \\
\hline C16:0 & 5.21 & 5.20 & 5.16 & 5.48 & 5.20 \\
\hline C18:0 & 2.41 & 2.40 & 2.36 & 2.32 & 2.35 \\
\hline C18:1 & 27.10 & 27.09 & 26.91 & 26.71 & 27.07 \\
\hline $\mathrm{C} 18: 2$ & 45.91 & 45.36 & 45.85 & 45.90 & 45.68 \\
\hline C18:3 (Pinolenic acid) & 13.53 & 13.50 & 13.63 & 13.33 & 13.61 \\
\hline C18:3 (linolenic acid) & 1.46 & 1.48 & 1.49 & 1.60 & 1.51 \\
\hline $\mathrm{C} 20: 0$ & 0.68 & 0.67 & 0.68 & 0.74 & 0.68 \\
\hline $\mathrm{C} 20: 2$ & 1.02 & 1.05 & 1.05 & 1.11 & 1.04 \\
\hline Trans-C18:2 & 2.23 & 2.23 & 2.24 & 2.09 & 2.24 \\
\hline Poly-unsaturated fatty acid (PUFA) & 61.92 & 61.39 & 62.02 & 61.94 & 61.85 \\
\hline Unsaturated fatty acid (UFA) & 89.02 & 88.48 & 88.93 & 88.65 & 88.92 \\
\hline Saturated fatty acid (SFA) & 8.30 & 8.27 & 8.20 & 8.54 & 8.23 \\
\hline
\end{tabular}

fatty acids (88.48\%-89.02\%), and among these, linoleic acid is most abundant $(45.36 \%-45.91 \%)$, followed by oleic acid (26.71\%-27.10\%), comparable to that reported by Wang et al. ${ }^{[5]}$. It is generally recognized that unsaturated fatty acids can influence the fluidity and permeability of the cell membrane. Linoleic acid (C18:2) is important for the healthy growth of human skin, and oleic acid (C18:1) has positive effects on cardiovascular diseases prevention ${ }^{[34]}$. Palmitic acid (C16:0) and stearic acid (C18:0) are the dominant saturated fatty acids, which is in good agreement with that reported by Imbs et al. ${ }^{[35]}$. These two saturated fatty acids comprise $8.20 \%-8.54 \%$ of total fatty acids, render the oil resistant to oxidative rancidity. The fatty acid profile of $P$. koraiensis nut oil makes it desirable with respect to nutrition and it may be used in food industry, for example, as edible cooking oil, as frying oil, as salad oil, or for the manufacture of margarine.

According to classification of vegetable oils by Dubois et al. ${ }^{[36]}$, the $P$. koraiensis nut oil, containing a high content of linoleic and oleic acid, is classified as a polyunsaturated oil. This class includes a large quantity of vegetable oils such as sunflower, corn, sesame and wheat germ oils. Besides being used in the food industry, the oils with a high content of polyunsaturated fatty acid, such as $P$. koraiensis nut oil, have the potential to be used in the cosmetics industry ${ }^{[37]}$.

Pinolenic acid, typically present only in conifer nut oil, is $13.33 \%-13.63 \%$ in P. koraiensis nut oil, similar to that reported by Xie et al. ${ }^{[28]}$. Lee et al. ${ }^{[38]}$ enriched the content of the pinolenic acid in $P$. koraiensis nut oil up to $45.1 \%$ using urea complexation and this concentration may enhance hepatic low-density lipoprotein (LDL) uptake and thus have LDL-lowering properties, indicating $P$. koraiensis nut oil may be a valuable source for pharmaceutical application.

The fatty acid compositions differed only slightly between the different extraction methods, indicating that the extraction method has little impact on the lipid profiles of the pine nut oil produced.

\subsection{Content and Composition of the Tocopherols and Tocotrienols}

Tocopherols and tocotrienols are natural antioxidants in most vegetable oils. Table 4 shows that the total contents of tocopherols and tocotrienols of the pine nut oils ranged from 27.65 to $37.52 \mathrm{mg} / 100 \mathrm{~g}$, lower than that reported for Pinus sibrica nut oils $(46.6-49.6 \mathrm{mg} / 100 \mathrm{~g})^{[39]}$, Curcurbita maxima seed oil $(418.66 \mathrm{mg} / 100 \mathrm{~g})^{[18]}$, Chenopodium Quinoa Willd. seed oil (72.78-336.00 mg/100 g) ${ }^{[19]}$, and Punica granatum L. seed oils $(135.3-524.6 \mathrm{mg} / 100 \mathrm{~g})^{[40]}$, but higher than that of walnut oil $(24.9 \mathrm{mg} / 100 \mathrm{~g})$, almond oil $(25.0 \mathrm{mg} / 100 \mathrm{~g})$, and peanut oil $(4.8 \mathrm{mg} / 100 \mathrm{~g})^{[41]}$.

$\alpha$-tocopherol is the most abundant, accounting for $46.87 \%-54.42 \%$ of the total tocopherols and tocotrienols, followed by $\gamma$-tocopherol. While $\alpha$-tocopherol is considered to be of most biological importance as a the vitamin $\mathrm{E}$ analogue, $\gamma$-tocopherol is reported to be more effective in preventing cellular damage induced by cytokines ${ }^{[42]}$.

The total contents of tocopherol and tocotrienol in descending order is $\mathrm{HECCO}>\mathrm{SEO}>\mathrm{CPO}>\mathrm{HEO}>\mathrm{HPO}$. The oils from hexane extraction of cold-pressed cake and sub-critical extraction are richest in vitamin $\mathrm{E}$, while the oil from hot pressing has the lowest contents of tocopherols and tocotrienols, which may be attributed that the high-temperature roasting involved in the hot pressing rendered the vitamin E destroyed.

\subsection{Oxidation Stability}

Rancimat test was carried out to measure the oxidation stability of the pine nut oils, and the oxidation induction time was determined (Table 5).

The oxidation induction time of the oils is 3.12-6.91 h, comparable to the walnut oil ${ }^{[41]}$, and the values in descending order is $\mathrm{HECCO}>\mathrm{HEO}>\mathrm{CPO}>\mathrm{SEO}>\mathrm{HPO}$. The pine nut oils from hexane extraction, cold pressing, and sub-critical extraction

Table 4 Contents of tocopherols and tocotrienols in pine nut oils

\begin{tabular}{|c|c|c|c|c|c|}
\hline Tocol (mg/100 g) & $\mathrm{CPO}$ & HPO & HEO & HECCO & SEO \\
\hline$\alpha$-Tocopherol & $16.14 \pm 0.02$ & $12.96 \pm 0.05$ & $15.59 \pm 0.04$ & $18.25 \pm 0.09$ & $19.69 \pm 1.02$ \\
\hline$\gamma$-Tocopherol & $11.29 \pm 0.09$ & $10.29 \pm 1.01$ & $11.72 \pm 0.06$ & $14.46 \pm 2.03$ & $12.40 \pm 0.07$ \\
\hline$(\beta+\gamma)$-Tocotrienol & $4.39 \pm 0.01$ & $4.49 \pm 0.01$ & $4.26 \pm 0.01$ & $4.81 \pm 0.01$ & $4.09 \pm 0.02$ \\
\hline Total tocol content & $31.82 \pm 2.12$ & $27.65 \pm 1.35$ & $31.57 \pm 1.68$ & $37.52 \pm 3.01$ & $36.18 \pm 2.26$ \\
\hline
\end{tabular}


Table 5 The oxidation induction time of the pine nut oils

\begin{tabular}{ccccccc}
\hline & CPO & HPO & HEO & HECCO & SEO \\
\hline Oxidation induction time $(\mathrm{h})$ & $4.96 \pm 0.02$ & $3.12 \pm 0.02$ & $5.27 \pm 0.03$ & $6.91 \pm 0.02$ & $4.93 \pm 0.01$ \\
\hline
\end{tabular}

has better oxidation stability, while the oil from hot pressing had the shortest oxidation induction time, showing the similar trend with the content of vitamin $\mathrm{E}$. The result might be due to that the vitamin $\mathrm{E}$ are the main contributors to the antioxidant stability of the pine nut oils. Arranz et al. ${ }^{[41]}$ also found that a significant correlation between 2,2-diphenyl-1-picrylhydrazyl radical (DPPH) scavenging values of non-polar fraction and tocopherol content.

\subsection{Potential Application of $P$. koraiensis Nut Oils Obtained by Different Extraction Technologies}

Based on the above physicochemical and antioxidant evaluations, the $P$. koraiensis nut oils could be a good source of edible oil. Considering the increased need for affordable sources of healthy plant edible oil in developing countries, the $P$. koraiensis could be one of the good woody candidates for closing the gap between the demand and production of vegetable oils.

Furthermore, the various features of the resultant oils from the different extraction procedures may enable the pine nut oil to find a wide range of utilization. The oils from cold-pressing and sub-critical extraction can be used in cosmetology. Additionally considering the high pinolenic acid content, the relatively high yield and low cost, the oil obtained by hexane extraction may be used as raw material to obtain products with further enriched content of pinolenic acid for pharmaceutical application.

\section{Conclusions}

As we know, little detailed research has been focused on physicochemical properties, fatty acid profiles, and tocopherol compositions of $P$. koraiensis nut oils obtained by different extraction technologies. The results show that $P$. koraiensis nuts consist of high level of oil $(68.67 \%)$. The pine nut oils are rich in linoleic acid, oleic acid, and pinolenic acid, and contained about $36 \mathrm{mg} / 100 \mathrm{~g}$ vitamin $\mathrm{E}$, indicating that $P$. koraiensis nut oil has a high nutritive value and potential health benefits, and may be suitable for a wide range of edible oil application.

Furthermore, various physicochemical properties of resultant oils from different extraction procedures and different features of the extraction techniques allow the multiple utilization of $P$. koraiensis nut oil in edible oil, cosmetic, and pharmaceutical industry. Thus industrial scale production of the $P$. koraiensis nut is herein recommended.

\section{Conflict of Interest}

The authors declare that there is no conflict of interest.

\section{References}

[1] Ciesla W M. Non-wood forest products from conifers[J]. Non-Wood Forest Products (FAO), 1998, 72-75.

[2] KAYIN X, ELIZABETH A M, PHILIP C C. A review of the potential health benefits of pine nut oil and its characteristic fatty acid pinolenic acid[J]. Journal of Functional Foods, 2016, 2(3): 464-473.
[3] DARRELL S, RAFAEL H, MARK Z, et al. Extraction of rice brain oil using supercritical carbon dioxide and propane[J] Journal of American Oil Chemists Society, 2006, 83(10): 885-891.

[4] HERRERO M, CIFUENTES A, IBANEZ E. Sub- and supercritical fluid extraction of functional ingredients from different natural sources: Plants, food-by-products, algae and microalgae: A review[J]. Food Chemistry, 2006, 9(8): 136-148.

[5] WANG G L, MA C G, WANG D Z, et al. Extraction of pine nut oil and analysis of its physicochemical properties[J]. China Oils and Fats, 2010, 35(2): 69-71.

[6] HE D P, LI L J, FU S. Production of pine nut oil and its microencapsulation[J]. China Oils and Fats, 2003, 28(2): 34-36.

[7] ZHU X M, RUAN X, HU J N, et al. Characteristics of positional fatty acid composition and distribution in Pinus koraiensis seed oil[J]. Science and Technology of Food Industry, 2012, 33(10): 65-68.

[8] DONG Y, LIU H P, LIU Y K, et al. Extraction process of pine nut oil and fatty acid composition analysis of three pine nut oils[J]. China Oils and Fats, 2017, 42(4): 8-11.

[9] ZHANG M, LIANG S H, YANG M, et al. Physicochemical properties and fatty acid compositions of pine nut oils with different varieties[J]. Journal of Henan University of Technology, 2017, 38(6): 26-31.

[10] CHANG C, RUAN Q J, BAO Y H, et al. Fatty acid composition and antioxidant activity of pine nut oils from different mountains[J]. Journal of Northeast Forestry University, 2017, 45(4): 84-87.

[11] BAO Y H, GUO Y. Optimization of ultrasonic-assisted aqueous enzymatic extraction of pine nut oil and its oxidative stability[J] Food Science, 2016, 37(22): 60-68.

[12] MA W J, QI B K, WANG J, et al. Effects of pine nut oil extracted by different methods and microwave heating on quality of oil[J]. Food and Nutrition in China, 2015, 21(3): 50-54.

[13] HORWTIZ W. Official methods of analysis of the AOAC, 17th Edn. AOAC[J]. Journal of AOAC International, 2000, 49: 1-28.

[14] VAN SOEST P J, ROBERTSON J B, LEWIS B A. Methods for dietary fiber, neutral detergent fiber, and non-starch carbohydrates in relation to animal nutrition[J]. Journal of Dairy Science, 1991, 74: 3583-3597.

[15] DUBOIS M, GILLES K A, HAMILTON J K, et al. Colorimetric method for determination of sugar and related substances $[\mathrm{J}]$. Analytical Chemistry, 1956, 2(8): 350-356.

[16] GB 5009.2-2016, National Health and Family Planning Commission of the People's Republic of China. Determination of the relative density of food[S]. Beijing: China Standard Publishing House, 2016.

[17] HALBAUT L, BARBE C, AROZTEGUI M, et al. Oxidative stability of semi-solid excipient mixtures with corn oil and its implication in the degradation of vitamin $\mathrm{A}[\mathrm{J}]$. International Journal of Pharmaceutics, 1997, 14(7): 31-40.

[18] REZIG L, CHOUAIBI M, MSAADA K, et al. Chemical composition and profile characterisation of pumpkin (Cucurbita maxima) seed oil[J]. Industrial Crops and Products, 2012, 3(7): 82-87.

[19] PRZYGODA K, WEJNEROWSKA G. Extraction of tocopherol-enriched oils from Quinoa seeds by supercritical fluid extraction[J]. Industrial Crops and Products, 2015, 6(3): 41-47.

[20] KADRI N, KHETTAL B, AID Y, et al. Some physicochemical characteristics of Pinus (Pinus halepensis Mill., Pinus pinea L., Pinus pinaster and Pinus canariensis) seeds from North Algeria, their lipid profiles and volatile contents[J]. Food Chemistry, 2015, 188: 184-192.

[21] WOLLF R L, BAYARD C C. Fatty acid composition of some pine seed oils[J]. Journal of the American Oil Chemists' Society, 
1995, 72(9): 1043-1046.

[22] NERGIZ C, DÖNMEZ İ. Chemical composition and nutritive value of Pinus pinea L. seeds[J]. Food Chemistry, 2004, 86(3): 365-368.

[23] KADRI N, KHETTAL B, YAHIAOUIZAIDI R, et al. Analysis of polar lipid fraction of Pinus halepensis Mill. seeds from North Algeria[J]. Industrial Crops and Products, 2013, 51: 116-122.

[24] CHIVANDI E, DACIDSON B C, ERLWANGER K. A comparison of the lipid and fatty acid profiles from the kernels of the fruit (nuts) of Ximenia caffra and Ricinodendron rautanenii from Zimbabwe[J]. Industrial Crops and Products, 2008, 27(1): 29-32.

[25] ARYA S S, SALVE A R, CHANUHAN S. Peanuts as functional food: a review[J]. Journal of Food Science \& Technology, 2016, 53(1): 31-41.

[26] HE Z, ZHU H, LI W, et al. Chemical components of cold pressed kernel oils from different Torreya grandis cultivars[J]. Food Chemistry, 2016, 20(9): 196-202.

[27] BALTA M F, YARILGAC T, ASKIN M A, et al. Determination of fatty acid compositions, oil contents and some quality traits of hazelnut genetic resources grown in eastern Anatolia of Turkey[J]. Journal of Food Composition \& Analysis, 2006, 19(6): 681-686.

[28] XIE K, MILES E A, CALDER P C. A review of the potential health benefits of pine nut oil and its characteristic fatty acid pinolenic acid[J]. Journal of Functional Foods, 2016, 2(3): 464-473.

[29] NEHDI I. Characteristics, chemical composition and utilisation of Albizia julibrissin seed oil[J]. Industrial Crops \& Products, 2011, 33(1): 30-94.

[30] BACHHETI R K, RAI I, JOSHI A, et al. Physico-chemical study of seed oil of Prunus armeniaca L. grown in Garhwal region (India) and its comparison with some conventional food oils[J] International Food Research Journal, 2012, 19(2): 577-581.

[31] GB 1535-2017, The state administration of quality supervision, inspection and quarantine of the People's Republic of China Soybean oil[S]. Beijing: China Standard Publishing House, 2017.
[32] KASOTE D M, BADHE Y S, HEGEDE M V. Effect of mechanical press oil extraction processing on quality of linseed oil[J]. Industrial Crops \& Products, 2013, 42(1): 10-13.

[33] QB/T 4079-2010, China federation of light industry, massage base oil, massage oil[S]. Beijing: China Light Industry Press, 2010.

[34] SKOLNIK P, EAGLSTEIN W H, ZIBOH V A. Human essential fatty acid deficiency: treatment by topical application of linoleic acid[J]. Archives of Dermatology, 1977, 113(7): 939-941.

[35] IMBS A B, NEVSHUPOVA N V, PHAM L Q. Triacylglycerol composition of Pinus koraiensis seed oil[J]. Journal of the American Oil Chemists Society, 1998, 75(7): 865-870.

[36] DUBOIS V, BRETON S, LINDER M, et al. Fatty acid profiles of 80 vegetable oils with regard to their nutritional potential[J]. European Journal of Lipid Science \& Technology, 2007, 109(7): 710-732.

[37] STUPP T, DE FREITAS R A, SIERAKOWSKI M R, et al Characterization and potential uses of Copaifera langsdorfii seeds and seed oil[J]. Bioresource Technology, 2008, 99(7): 2659-2663.

[38] LEE J W, LEE K W, LEE S W, et al. Selective increase in pinolenic acid (all-cis-5,9,12-18:3) in Korean pine nut oil by crystallization and its effect on LDL-receptor activity[J]. Lipids, 2004, 39(4): 383-387.

[39] ZADERNOWSKI R, NACZK M, Czaplicki S. Chemical composition of Pinus sibirica nut oils[J]. European Journal of Lipid Science \& Technology, 2010, 111(7): 698-704.

[40] FERNANDES L, PEREIRA J A, LOPEZ-CORTES I, et al. Fatty acid, vitamin $\mathrm{E}$ and sterols composition of seed oils from nine different pomegranate (Punica granatum L.) cultivars grown in Spain[J]. Journal of Food Composition \& Analysis, 2015, 39: 13-22.

[41] ARRANZ S, CERT R, PEREZJIMENEZ J, et al. Comparison between free radical scavenging capacity and oxidative stability of nut oils[J]. Food Chemistry, 2008, 110(4): 985-990.

[42] BURNETT T S, TANAKA Y, HARWOOD P J, et al. Mechanisms of phytochemical inhibition of carcinogenesis: elucidating the role of $\gamma$-tocopherol in nutrition[J]. Acs Symposium, 1998, 70(1): 45-58. 